\title{
Energy Losses in Cross Junctions
}

\author{
Zachary B. Sharp'; Michael C. Johnson, P.E., M.ASCE ${ }^{2}$; Steven L. Barfuss, P.E., M.ASCE ${ }^{3}$; and \\ William J. Rahmeyer, P.E., M.ASCE ${ }^{4}$
}

\begin{abstract}
Energy losses occurring in pipe junctions have been studied for many years. Head loss coefficients $(K)$ are commonly used to characterize losses across elbows, tees, crosses, valves, and other pipe fittings. When accurate values of $K$ are used, the flow rate and corresponding total head at any location in a pipe network can be calculated. While $K$ is well defined for most pipe junctions and fittings, the literature has limited documentations of $K$ for crosses. This study was commissioned to determine $K$ for a wide range of flow combinations in a pipe cross with equal diameter pipes and varied flow combinations. This study provides and innovatively presents over 1,000 experimental values of $K$ for designing and analyzing equal diameter pipe crosses.
\end{abstract}

DOI: $10.1061 /(\mathrm{ASCE}) \mathrm{HY} .1943-7900.0000126$

CE Database subject headings: Energy losses; Coefficients; Pipes; Hydraulic design.

Author keywords: Local loss; Loss coefficient; K-factor; Energy loss; Cross; Pipe junction; Hydraulic design.

\section{Background}

Determining energy loss in pipe fittings and junctions has been given considerable attention. Currently, there are standardized head loss coefficients $(K)$ for elbows (Crane Co. 1988), tees (Costa et al. 2006; Oka and Ito 2005), pipe expansions and contractions (Finnemore and Franzini 2006), valves, and other fittings (Crane Co. 1988). There has been extensive research on different types of tees, including tees with different radius to diameter ratios (Ito and Imai 1973), different area ratios (Serre et al. 1994), different approach angles of the branching pipe (Oka and Ito 2005), and tees with rectangular cross sections (Ramamurthy and Zhu 1997; Ramamurthy et al. 2006). The literature however contains little energy loss information for crosses, which are commonly used in water distribution systems and fire flow distribution systems. The only head loss information for crosses known to the writers is provided by Miller (Miller 1978), although these data are only valid for a square edged cross (zero radius). No other comprehensive data sets have been found in the literature, so no comprehensive procedure for analyzing crosses in piping networks currently exists.

Computer software packages are also incomplete in their analysis of pipe junctions. These software applications usually allow a constant loss coefficient for a cross or other junction to be

\footnotetext{
${ }^{1}$ Graduate Student, Utah Water Research Laboratory, Logan, UT 84321. E-mail: zac.sharp@aggiemail.usu.edu

${ }^{2}$ Research Assistant Professor, Utah State Univ., 8200 Old Main Hill, Logan, UT 84322 (corresponding author). E-mail: mikejnsn@ engineering.usu.edu

${ }^{3}$ Research Assistant Professor, Utah State Univ., 8200 Old Main Hill, Logan, UT 84322. E-mail: barfuss@engineering.usu.edu

${ }^{4}$ Professor and Chair, Utah State Univ., 8200 Old Main Hill, Logan, UT 84322. E-mail: rahmeyer@enginering.usu.edu

Note. This manuscript was submitted on September 17, 2008; approved on June 23, 2009; published online on June 25, 2009. Discussion period open until June 1, 2010; separate discussions must be submitted for individual papers. This technical note is part of the Journal of Hydraulic Engineering, Vol. 136, No. 1, January 1, 2010. CASCE, ISSN 0733-9429/2010/1-50-55/\$25.00.
}

input by the user for the analysis, generally as a loss in the downstream pipe. This approach is not always practical or entirely accurate (Wood et al. 1993).

One challenging aspect of hydraulically analyzing a cross is the number of possibilities for flow direction and distribution. There are four basic flow scenarios that can occur in a cross: (1) flow into one leg and out of three legs (dividing flow); (2) flow into three legs and out of one leg (combining flow); (3) flow into two perpendicular legs and out of two perpendicular legs (perpendicular flow); and (4) flow into two opposite legs and out of two opposite legs (colliding flow). Fig. 1 illustrates these four flow scenarios. For any given flow condition, three values of $K$ are required to completely analyze a cross. This study provides the head loss information for each leg of a cross to aid in design and analysis calculations of pipe networks containing equal diameter crosses.

\section{Theoretical Background}

In the design of pipelines or water distribution systems, the flow is calculated using the total energy loss in a particular pipe or around a loop of pipes coupled with the conservation of mass at junctions. The total head $(E)$ at a location in the pipe can be calculated as

$$
E=\frac{P}{\gamma}+Z+\alpha \frac{V^{2}}{2 g}
$$

where $P=$ pressure; $\gamma=$ specific weight; $Z=$ elevation above the pipe centerline; $\alpha=$ kinetic energy correction factor; $V=$ average pipe velocity; and $g=$ acceleration due to gravity. Since flow was turbulent during this experiment, $\alpha$ was assumed to be one in all calculations (Finnemore and Franzini 2006). The head loss in a pipe or pipe network is the difference in $E$ between two locations in that pipe or pipe network. Pipelines incur energy losses due to friction and local or minor losses, which may include energy lost at elbows, tees, crosses, valves, and other fittings. The head loss due to local losses, $H_{L}$ is commonly calculated by using a loss coefficient $K$ as 


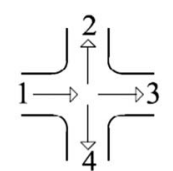

A) Dividing Flow

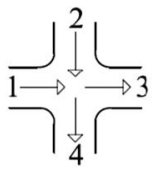

C) Perpendicular Flow

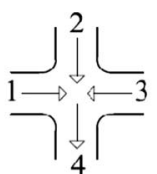

B) Combining Flow

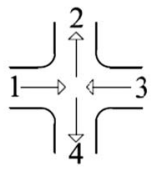

D) Colliding Flow
Fig. 1. Four possible flow scenarios in a cross

$$
H_{L}=K \frac{V^{2}}{2 g}
$$

whereas the head loss due to friction, $H_{F}$, is commonly found using a friction factor, $f$, as

$$
H_{F}=\frac{f L}{D} \frac{V^{2}}{2 g}
$$

where $L=$ pipe length and $D=$ inside diameter of the pipe. Loss coefficients can be found by measuring the flow and pressure in a pipe to determine $E$ and can be evaluated from the energy equation (Finnemore and Franzini 2006)

$$
E_{1}=E_{i}+\sum H_{F}+\sum H_{L}
$$

where $E_{1}$ and $E_{i}=$ total head at upstream and downstream locations. In cases where all pipe parameters of a cross are known, the flow $Q$ and $P$ in each leg can be measured, leaving $K$ and $f$ as the only remaining unknowns in the energy equation. To determine $H_{F}$ in a pipe, conventional values of $f$ can be used or $f$ for the pipe can be experimentally determined. With friction accounted for, the actual head loss in the tested fitting can be established and $E$ at the entrance or exit of each cross leg can be calculated using Eq. (1). Once the friction factor is established, $K$ is the only unknown and can be determined from

$$
E_{1}-E_{i}=K_{1-i} \frac{V_{i}^{2}}{2 g}
$$

where $K_{1-i}=$ energy loss coefficient from Leg 1 to leg $i$ and $V_{i}$ $=$ average flow velocity in leg $i$.

\section{Experimental Procedure}

All data for this study were collected at the Utah Water Research Laboratory (UWRL). Water was supplied to the test setup from First Dam, a 104,846 $\mathrm{m}^{3}$ impoundment located on the Logan River near the UWRL. This study was designed to determine $K$ in all legs of a cross for a wide variety of possible flow distributions in each of the four basic flow scenarios for the cross described previously. A test bench was constructed using standard 152.5 -mm carbon steel pipe with a 154.05 -mm inner diameter. Fig. 2 shows a layout of the test section. The test setup contained a minimum of $20 \mathrm{D}$ of approach pipe in each leg of the cross and had pressure taps located $6 D$ from the entrance/exit of the cross which were used to measure pressure on the inlet and outlet pipes. These locations were based on guidelines given by the Instrument Society of America [Instrument Society of America (ISA) 1988].

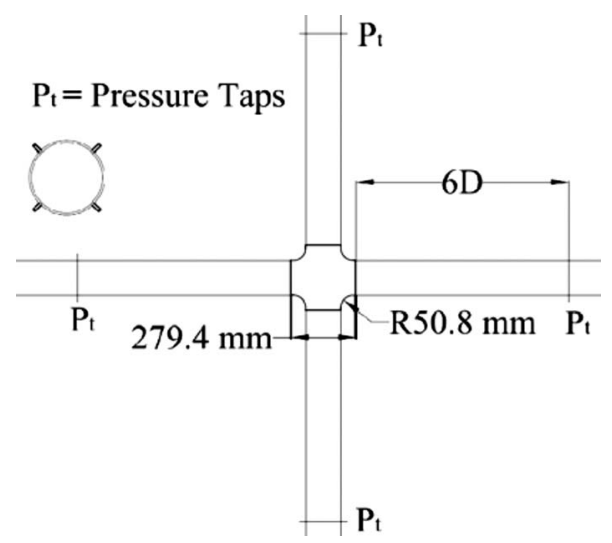

Fig. 2. Overview of the test setup

Four pressure taps on each leg, as shown in Fig. 2, provided accurate average pressure readings. All burrs were removed from the pressure taps to eliminate errors in differential pressure measurements. The radii of the corners within the cross were 50.8 $\mathrm{mm}$, for a radius to diameter ratio of approximately 0.33 .

The test bench was designed to measure flow on three of the four cross legs with calibrated magnetic flow meters. The flow in the fourth leg was calculated using conservation of mass. The pipe pressure was measured in one leg of the cross and the differential pressure was measured from Leg 1 to leg $i$ using Rosemount transmitters. With $Q, P$, and pipe parameters known, $K$ was calculated in each leg for each flow condition using Eq. (5).

\section{Experimental Results}

Because there are many flow scenario possibilities in a cross, presenting the data in a concise manner is a challenge. After careful consideration, the writers chose to present $K$ on several contour plots, as shown in Figs. 3-14, as a function of the ratio of the flow in each leg $\left(Q_{i}\right)$ to the total flow entering the cross $\left(Q_{t}\right)$. Each flow scenario has three charts, one for each $K: K_{1-2}, K_{1-3}$, and $K_{1-4}$. The legend in each figure shows the direction of flow in each cross leg. For the dividing and combining flow scenarios (Figs. 3-8), $K$ is presented on ternary plots because three of the four cross legs have common flow directions requiring three axes

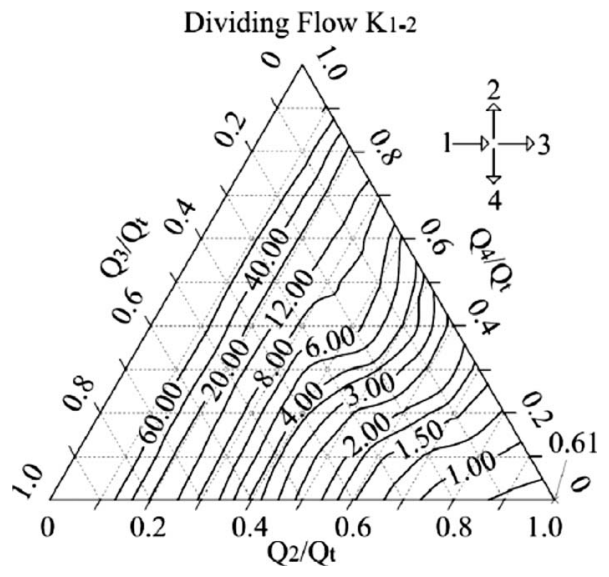

Fig. 3. Dividing flow $K_{1-2}$ 
Dividing Flow K1-3

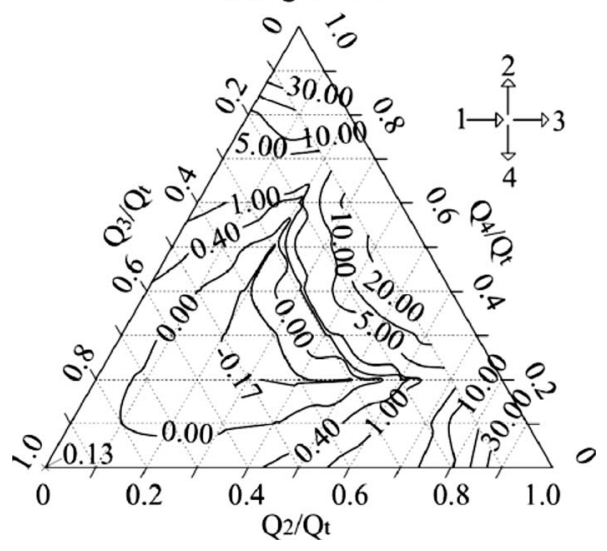

Fig. 4. Dividing flow $K_{1-3}$

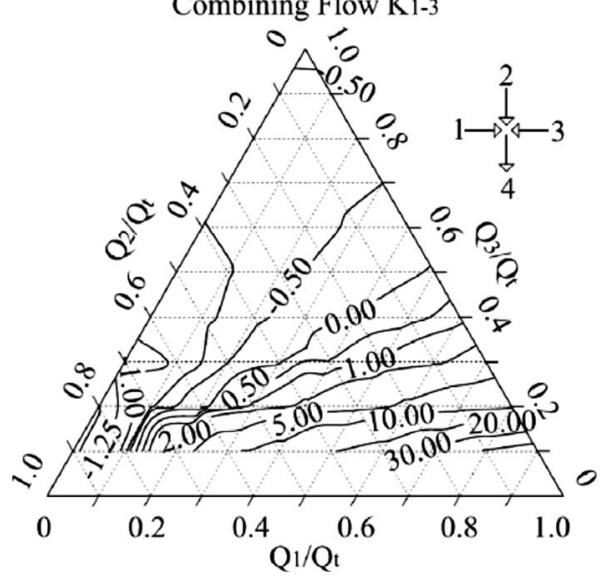

Fig. 7. Combining flow $K_{1-3}$

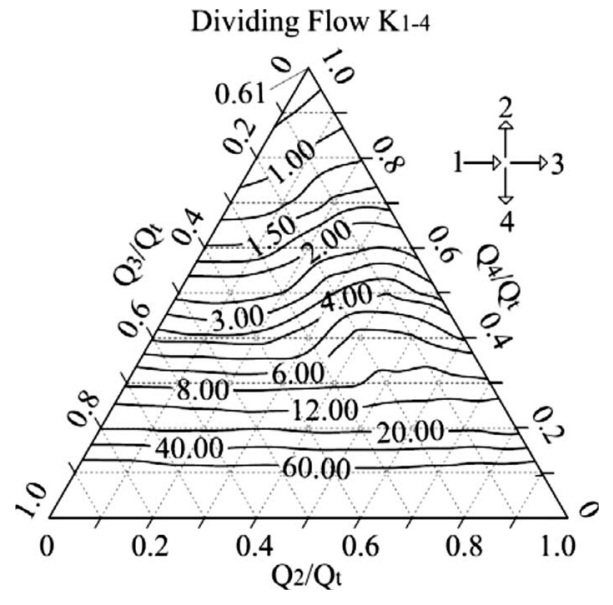

Fig. 5. Dividing flow $K_{1-4}$

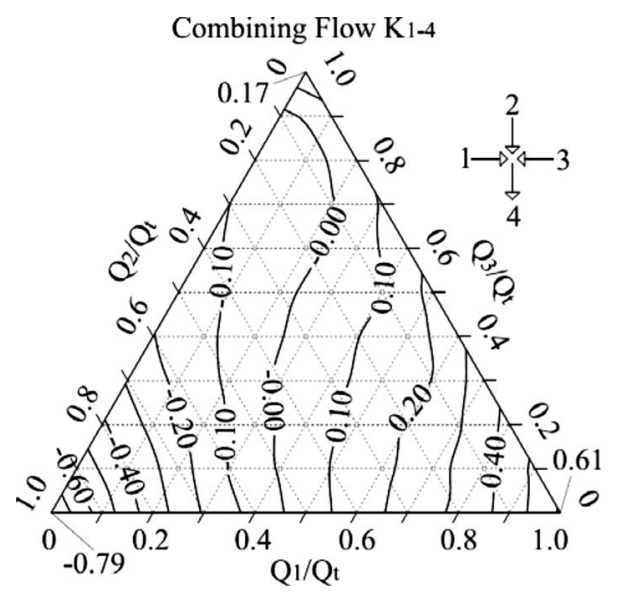

Fig. 8. Combining flow $K_{1-4}$

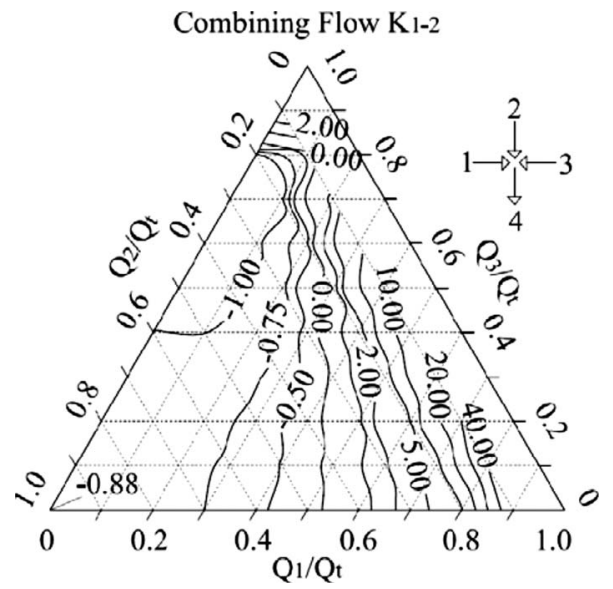

Fig. 6. Combining flow $K_{1-2}$

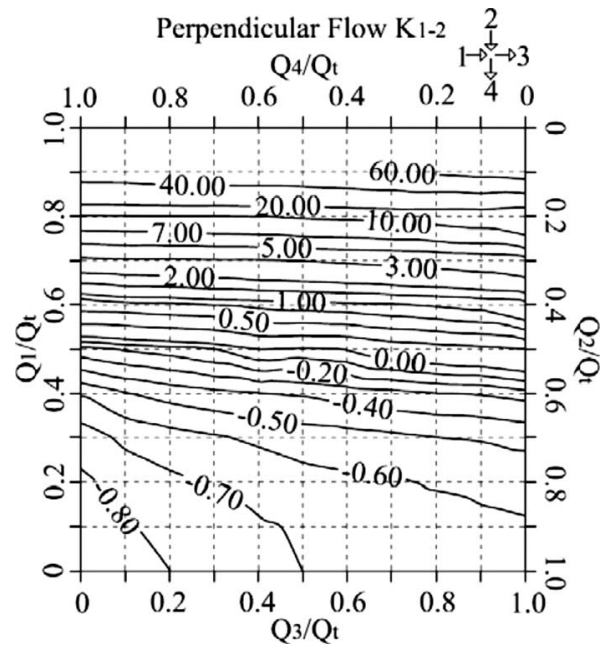

Fig. 9. Perpendicular flow $K_{1-2}$ 


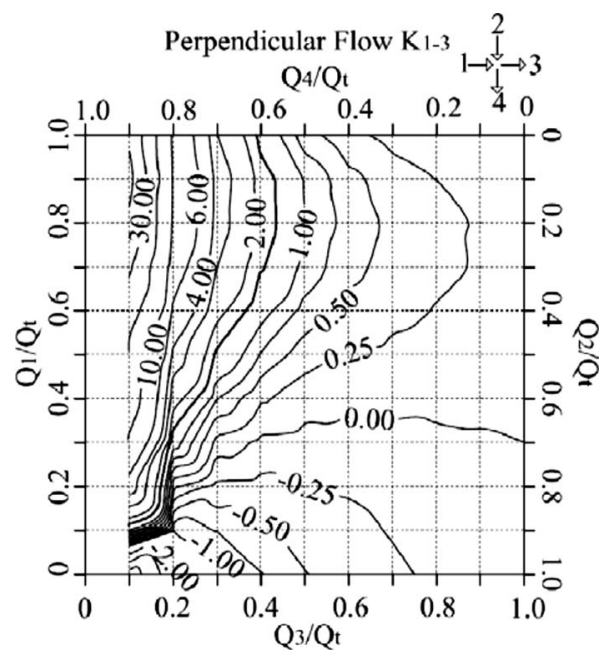

Fig. 10. Perpendicular flow $K_{1-3}$

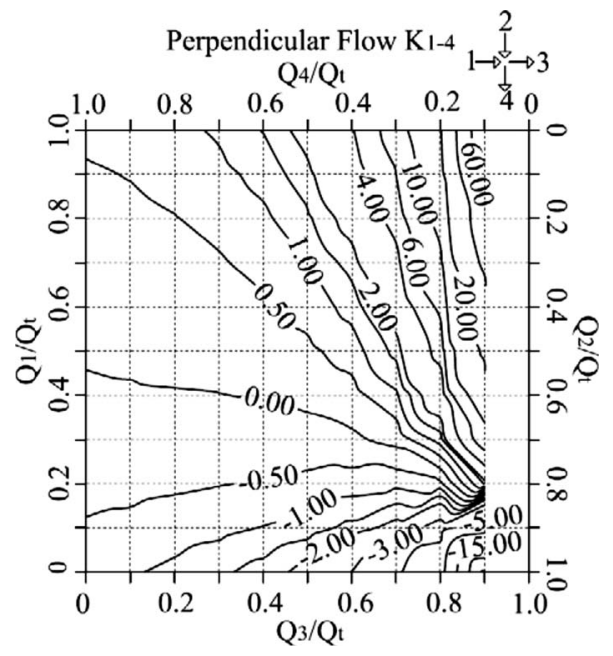

Fig. 11. Perpendicular flow $K_{1-4}$

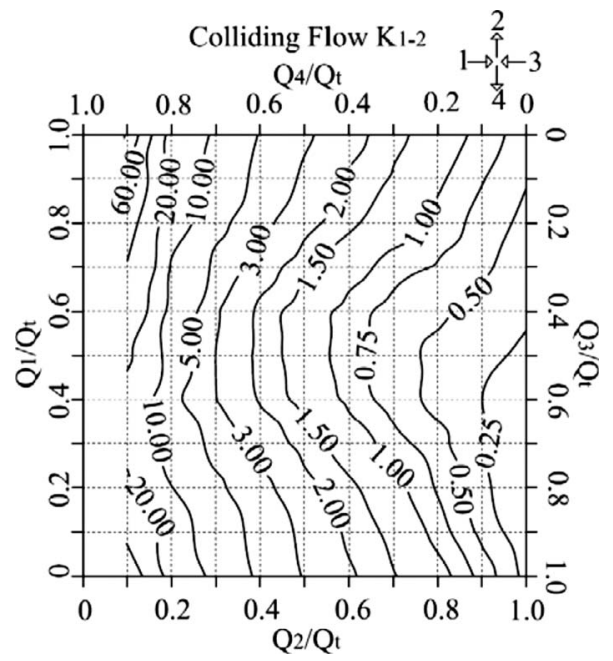

Fig. 12. Colliding flow $K_{1-2}$

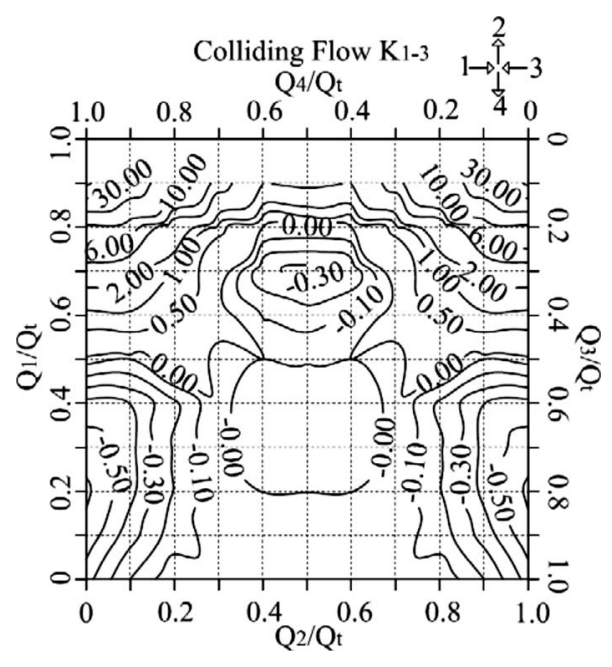

Fig. 13. Colliding flow $K_{1-3}$

to plot one data point. For the perpendicular and colliding flow scenarios, $K$ is plotted on $x-y$ coordinate square plots, as shown in Figs. 9-14.

\section{Using the Results}

All contour plots require either the flow in each cross leg or the desired flow ratios to be known in order to determine the correct value of $K$. If the flows are unknown, estimates of $K$ can be used and the solution can be obtained through an iterative process whereby $K$ s are updated with successive calculations of flow ratios from the flow rates in each leg of the cross. Also, to determine $E$ in each of the cross legs, $E$ in at least one leg must be known.

The following example problem illustrates how Figs. 3-14 can be used to obtain correct $K$ s. These $K$ values can be used in Eq. (5) to compute the energy loss in a cross. A special case arises when there is zero flow in one or more legs, in which case $K$ is undefined because the downstream leg has zero velocity, thereby making the solution for $K$ in Eq. (5) infinity or undefined. In most

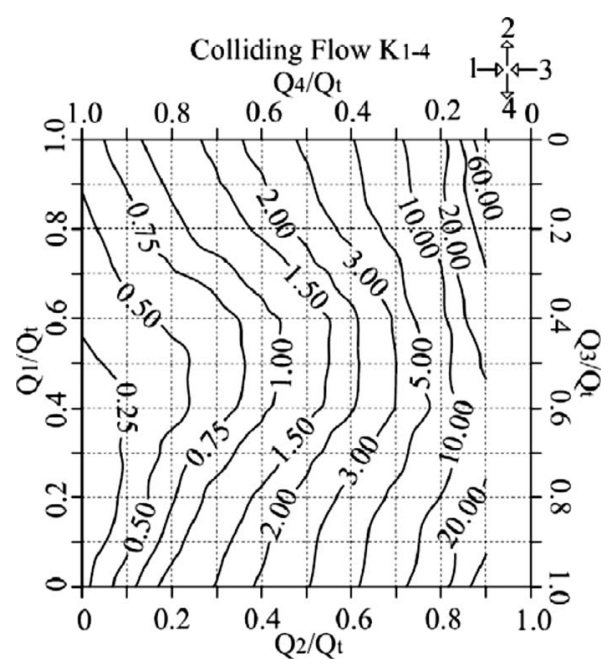

Fig. 14. Colliding flow $K_{1-4}$ 


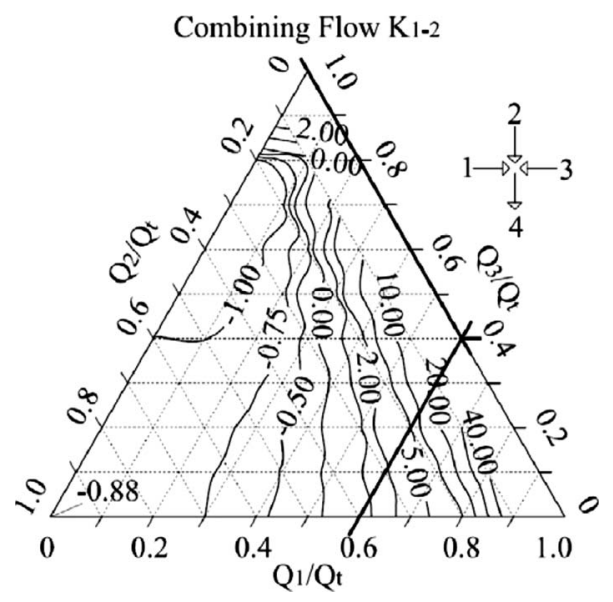

Fig. 15. Combining flowchart showing $K_{1-2}$ is $\infty$

cases the head will not need to be known in a zero flow leg; if the head is needed, it can be approximated as the average of the known head in the other legs. While a zero flow leg may be primarily of academic interest, the writers found it important to address this for completeness. The following example problem is based on the experimental data and deals with a zero flow leg. The same procedure for determining $K$ and $E$ in each leg can be used when there is flow in all four cross legs or in only two of the four cross legs.

\section{Example Problem}

Given: Leg 1 supplies $60 \%$ of the flow into the cross and has a measured pressure of $258.6 \mathrm{kPa}$. Leg 3 supplies the balance of the flow, Leg 2 has zero flow, and all of the flow exits through Leg 4. The water temperature is $5.44^{\circ} \mathrm{C}$ and the unit weight of water, $\gamma=9.807 \mathrm{kN} / \mathrm{m}^{3}$. The total flow into the cross from legs 1 to 3 is $Q_{t}=0.067 \mathrm{~m}^{3} / \mathrm{s}$ in a combining (or colliding, both apply in this case since Leg 2 has zero flow) flow scenario with a $0.154-\mathrm{m}$ diameter and a $0.0186 \mathrm{~m}^{2}$ cross-sectional area in all cross legs. Find the head in each of the cross legs.

Solution: With the flow ratios and total flow into the cross given, the flows in legs 1,3 , and 4 are easily determined as 0.040 , 0.027 , and $-0.067 \mathrm{~m}^{3} / \mathrm{s}$, respectively (+equals flow in to cross,

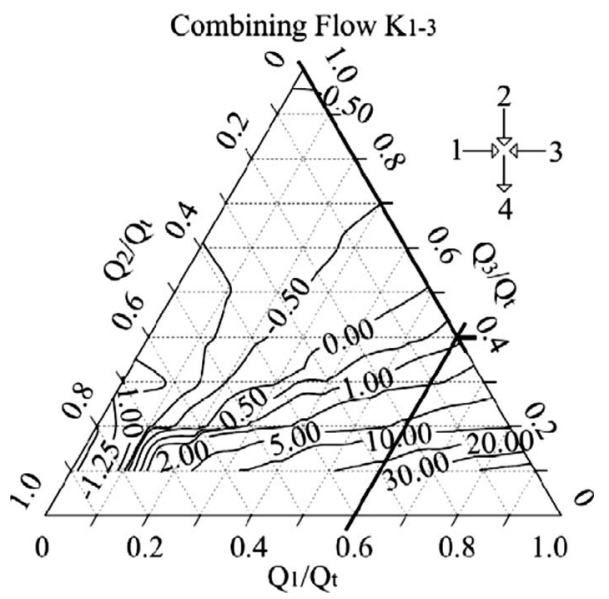

Fig. 16. Combining flowchart showing $K_{1-3}$ is 0.78

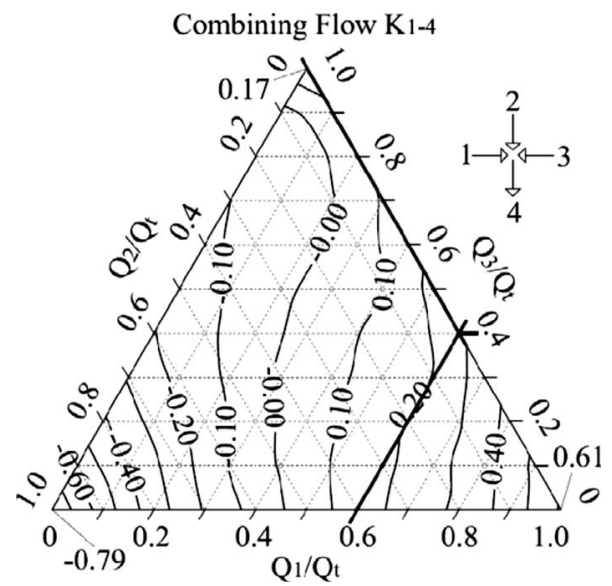

Fig. 17. Combining flowchart showing $K_{1-4}$ is 0.28

- equals flow out of cross). The corresponding flow ratios $Q_{1} / Q_{t}$, $Q_{2} / Q_{t}$, and $Q_{3} / Q_{t}$ are $0.6,0.0$, and 0.4 , respectively. These flow ratios are the values used with the contour plots to determine the values of $K$. The $E$ in Leg 1 can be determined, assuming an elevation of zero using the pipe centerline as the datum, from Eq. (6) while the $E_{i}$ in subsequent pipes can be found using Eq. (7) with the loss coefficients determined from Figs. 6-8

$$
E_{1}=\frac{P_{1}}{\gamma}+\frac{Q_{1}^{2}}{2 g A^{2}}
$$

$$
E_{i}=E_{1}-K_{1-i} \frac{Q_{i}^{2}}{2 g A^{2}}
$$

so that $E_{1}=26.6 \mathrm{~m}$. Figs. $15-17$ show how to use the combining flow contour plots (Figs. 6-8) to determine the $K$ s needed for this example problem by plotting the flow ratios in each pipe on the appropriate figures. These flow ratio lines are the dark lines in the figures which are tied to the axes whose tick marks are parallel to the dark line. $K$ is the value from the contours where the flow ratio lines cross. In this example the values of $K$ are $K_{1-2}=\infty$, $K_{1-3}=0.78$, and $K_{1-4}=0.28$, as shown in Figs. $15-17$. In any case where $K=\infty$ this value will appear on a boundary as in this example. Using Eq. (7) with the values of $K$ from the contour plots, $E_{3}=26.5 \mathrm{~m}$ and $E_{4}=26.4 \mathrm{~m}$. Because Leg 2 has no flow $K_{1-2}$ $=\infty$. One way to obtain $E_{2}$ takes the average of the known energies in legs 1-4 which results in $26.5 \mathrm{~m}$. The actual $E_{2}$ during the experimental data collection was $26.42 \mathrm{~m}$ for a difference of 0.08 $\mathrm{m}$ or $-0.30 \%$. The maximum errors from computing the $E$ in the zero leg, or zero legs, by using the average of the known $E$ were $\pm 1.6 \%$ for all flow distributions and scenarios except when there is flow going straight through the cross with zero flow in either of the branching legs. In this case the errors were as great as $-3.1 \%$.

\section{Uncertainty of Results}

All measurements have uncertainty due to systematic and/or random errors, which propagate into the calculated values of $K$. Therefore, an uncertainty analysis of the results of this research was performed so that the bounds of error on $K$ could be established. The analysis followed ASME PTC 19.1-2005 (ASME 2006). 
This study determined over 1,000 experimental $K$ values ranging from -25.7 to 81.2 , of which only $2 \%$ of the values of $K$ had uncertainties greater than $10 \%$. All $K$ values had absolute uncertainties less than 0.13 (i.e., $K \pm 0.13$ ) except when $K$ was greater than 20, in which case absolute uncertainties were as great as 0.25 . Only when $K$ was quite small (i.e., $K \leq 0.20$ ) did some of the uncertainty values exceed $10 \%$.

Based on the uncertainty analysis performed, the data of this study are accurate enough for design and analysis. The values of $K$ with the highest relative uncertainties will not result in a significant change in calculated pipe energies because these values of $K$ are so small that there is effectively no head loss. The larger values of $K$ (i.e., $K \geq 5$ ) had smaller relative uncertainties that will not change the value of $K$ by more than $1 \%$.

\section{Discussions and Conclusions}

This study includes all flow conditions and distributions for the cross tested (radius to diameter ratio of 0.33 ). Because cross design can vary with application, it is expected that $K$ values will not be the same for crosses with substantially different designs. The user must therefore be mindful that, while this study provides insight into cross head loss, it does not claim to include all types of crosses in use. This study only addressed one cross design and size; future studies of fabricated crosses having sharp corners, reducing crosses, differing sizes, or even crosses having a larger radius of curvature would benefit design engineers.

It should be noted that the majority of the testing was performed with the maximum $V$ into the cross and the sum of the $V_{i}$ into the cross from all supply legs approximately $3.7 \mathrm{~m} / \mathrm{s}$. In addition, multiple data points were collected over a range of what the writers believe to be typical pipeline velocities and Reynolds numbers. The results showed that for flows within a range of Reynolds numbers between 30,000 and 450,000, the loss coefficients were consistent. Therefore, the writers believe the results of this study apply to all velocity ranges except in extreme cases. Velocities below $0.3 \mathrm{~m} / \mathrm{s}$ and above $4 \mathrm{~m} / \mathrm{s}$ were not tested in this study.

The results of this study provide information pertaining to head loss in crosses or other four-leg pipe junctions that was previously not available in the literature. Four different flow scenarios were tested in which the flow in each leg of the cross was varied from 0 to $100 \%$ on $10 \%$ increments. The flow and pressure in each leg of the cross were measured and values of $K$ were calculated using the measurements taken. Twelve contour plots displaying values of $K$ were developed to present the results of this study, with three plots for each flow scenario. These plots can be used as engineering tools for the design of pipe networks with crosses at junctions. It is anticipated that, at some point in the future, the developers of pipe network software may incorporate the results of this study into computer analysis software or other design calculations.

\section{Notation}

The following symbols are used in this technical note:

$A=$ cross-sectional area of the pipe $\left(\mathrm{m}^{2}\right)$;

$D=$ pipe diameter $(\mathrm{mm})$;

$E=$ total head at specified location in the pipe $(\mathrm{m})$;

$E_{i}=$ total head at location $i(\mathrm{~m}), i=1,2,3,4$;

$f_{i}=$ friction factor for leg $i$ in the cross (-);

$g=$ acceleration due to gravity $\left(\mathrm{m} / \mathrm{s}^{2}\right)$;

$H_{F}=$ head loss due to friction (m);

$H_{L}=$ head loss due to local losses (m);

$L=$ length of pipe from the cross edge to the pressure taps $(\mathrm{m})$;

$K=$ energy loss coefficient (-);

$K_{1-i}=$ energy loss coefficient from Leg 1 to leg $i(-), i$ $=1,2,3,4$;

$P=$ pressure at some location in the pipe $(\mathrm{kPa})$;

$P_{1}=$ pressure in Leg 1 of the pipe $(\mathrm{kPa})$;

$\Delta P_{1-i}=$ differential pressure between legs one and $i$ of the cross $(\mathrm{kPa})$;

$Q_{i}=$ flow rate in leg $i\left(\mathrm{~m}^{3} / \mathrm{s}\right), i=1,2,3,4 ;$

$Q_{t}=$ total flow rate into the cross $\left(\mathrm{m}^{3} / \mathrm{s}\right)$;

$V=$ average pipe velocity $(\mathrm{m} / \mathrm{s})$;

$V_{i}=$ average pipe velocity in leg $i(\mathrm{~m} / \mathrm{s})$;

$Z=$ pipe elevation at location of the pressure taps $(\mathrm{m})$; and

$\gamma=$ unit weight of water $\left(\mathrm{N} / \mathrm{m}^{3}\right)$.

\section{References}

ASME. (2006). "Test uncertainty." ASME PTC 19.1-2005, New York.

Costa, N. P., Maia, R., Proenca, M. F., and Pinho, F. T. (2006). "Edge effects on the flow characteristics in a 90 deg tee junction." $A S M E$ Trans. J. Fluids Eng., 128, 1204-1217.

Crane Co. (1988). "Flow of fluids through valves, fittings and pipe." Technical Rep. No. 410, Crane Co., Joliet, Ill.

Finnemore, E. J., and Franzini, J. B. (2006). Fluid mechanics with engineering applications, 10th Ed., McGraw-Hill, New York.

Instrument Society of America (ISA).(1988). "Control valve capacity test procedure.” ANSI/ISA-S75.02-1988, N.C.

Ito, H., and Imai, K. (1973). "Energy loss at $90^{\circ}$ pipe junctions." J. Hydr. Div., 99(HY9), 1353-1369.

Miller, D.S. (1978). "Internal flow systems." BHRA engineering series, Vol. 5, The British Hydromechanics Research Association (BHRA).

Oka, K., and Ito, H. (2005). "Energy losses at tees with large area ratios." ASME Trans. J. Fluids Eng., 127, 110-116.

Ramamurthy, A. S., and Zhu, W. (1997). "Combining flows in $90^{\circ}$ junctions of rectangular closed conduits." J. Hydraul. Eng., 123(11), $1012-1019$

Ramamurthy, A. S., Qu, J., and Zhai, C. (2006). "3D simulation of combining flows in $90^{\circ}$ rectangular closed conduits." J. Hydraul. Eng., 132(2), 214-218.

Serre, M., Odgaard, A. J., and Elder, R. A. (1994). "Energy loss at combining pipe junctions.” J. Hydraul. Eng., 120(7), 808-830.

Wood, D. J., Reddy, L. S., and Funk, J. E. (1993). "Modeling pipe networks dominated by junctions." J. Hydraul. Eng., 119(8), 949-958. 